\title{
INFILTRAÇÃO DA ÁGUA NO SOLO NO SISTEMA PEDOLÓGICO CAMPUS DO ARENITO, CIDADE GAÚCHA, NOROESTE DO ESTADO DO PARANÁ(1)
}

\author{
José Edézio Cunha ${ }^{(2)}$, Maria Teresa de Nóbrega ${ }^{(3)}$ \& Selma \\ Simões de Castro ${ }^{(4)}$
}

\begin{abstract}
RESUMO
Considerando a importância do conhecimento do comportamento hídrico das coberturas pedológicas para os estudos de prevenção e contenção dos processos erosivos, o presente trabalho foi realizado em uma vertente com sistema pedológico "Latossolo Vermelho eutrófico/Argissolo Vermelho eutrófico", oriundo do arenito Caiuá, localizado na fazenda experimental da Universidade Estadual de Maringá, município de Cidade Gaúcha, noroeste do Estado do Paraná. Após abordagem morfológica detalhada do sistema pedológico, realizaram-se ensaios de infiltrometria nos principais horizontes diagnósticos e suas respectivas transições em seis perfis de solos dispostos ao longo da vertente. A dinâmica hídrica da cobertura latossólica encontra-se marcada por um comportamento distinto entre a superfície e a subsuperfície. Os horizontes superficiais Ap, AB e, ou, BA exibem ao longo do tempo uma alternância de condições de umidade, ora mais úmidos, ora mais secos, devido à distribuição e intensidade das chuvas. Em profundidade, no horizonte $\mathrm{Bw}$, as condições hídricas dependem da movimentação da água vertical e lateral, não respondendo, portanto, diretamente às variações atmosféricas como na superfície. Na cobertura argissólica, o bloqueio da drenagem vertical ocorre no topo do Bt, gerando acima (horizonte $\mathrm{AE}$ ) uma zona mais constantemente úmida. De modo geral, os horizontes superficiais dos Argissolos não apresentam as alternâncias de umedecimento e secamento verificadas nos Latossolos; permanecem sempre mais úmidos do que aqueles, em razão dos fluxos hídricos laterais de montante.
\end{abstract}

Termos de indexação: fluxos hídricos, Latossolo, Argissolo.

(1) Parte da Tese de Doutorado do primeiro autor apresentada ao Departamento de Geografia da Universidade de São Paulo USP. Recebido para publicação em novembro de 2007 e aprovado em junho de 2008.

(2) Professor Adjunto do Curso de Geografia, Universidade Estadual do Oeste do Paraná - UNIOESTE. Rua Pernambuco 1777 , CEP 85960-000 Marechal Cândido Rondon (PR). E-mail: edezio@unioeste.br

(3) Professora Associada do Curso de Geografia, Universidade Estadual de Maringá - UEM. Av. Colombo 5790, CEP 87020-900 Maringá (PR). E-mail: mtnobrega@uol.com.br

(4) Professora Associada do Instituto de Estudos Sócio-Ambientais, Universidade Federal de Goiânia - UFGO. Campus II, CEP 74001-970 Goiânia (GO). E-mail: selma@iesa.ufg.br 


\title{
SUMMARY: WATER INFILTRATION IN THE SOIL SYSTEM CAMPUS DO ARENITO IN CIDADE GAUCHA COUNTY, NORTHEASTERN PARANA STATE
}

\begin{abstract}
Considering the importance of understanding the water status of pedological covers for studies of prevention and containment of erosive processes, this study was conducted on a slope with a pedological system composed of Red Latossol (Oxisol)/Red Argisol (Ultisol) derived from Caiuá sandstone, on an experimental farm of the Universidade Estadual de Maringá, Cidade Gaúcha, in Northwestern Paraná State. After a detailed morphologic description of the pedologic system, infiltration experiments were carried out in the main diagnostic horizons and the respective transitions of six soil profiles along the slope. The pattern of water dynamics in the latosolic cover is different in the surface and subsurface. Over the course of time, the surface horizons $A P, A B$ and/or BA have alternating humidity conditions, sometimes more humid and sometimes drier, according to the rain distribution and intensity. In deeper layers of the $B w$ horizon the water conditions depend on the vertical and lateral water movement, and are therefore not directly related to the atmospheric variations, as occur on the surface. In the podzolic cover a vertical drainage blockage was observed in the top of Bt horizon, generating above it (horizon AE) a more constantly humid zone. In general, unlike in the Latosols, humidity and dryness do not alternate in the surface horizons of the Argisol. As a result the Argisols are constantly more humid than Latosols due to lateral water flow from upslope.
\end{abstract}

Index terms: water flows, latosol, podzolic soil.

\section{INTRODUÇÃO}

A busca de soluções preventivas e corretivas para os processos erosivos laminares e lineares da região noroeste do Estado do Paraná vem sendo indicada por muitos pesquisadores como necessária e urgente. Esse desafio é constante em virtude da fragilidade natural da cobertura pedológica, de textura arenosa fina, oriunda do arenito Caiuá (Formação Caiuá do Grupo Bauru, Cretáceo Superior, da Bacia Sedimentar do Paraná) e do desmatamento generalizado, seguido de usos e manejos quase sempre intensivos e inadequados, iniciados há aproximadamente 60 anos, quando a região começou a ser ocupada.

Com a retirada do café no início da década de 1960, os solos passaram a ser cultivados com soja, trigo e pastagens. O uso intensivo de maquinários e a ausência ou inadequação de práticas conservacionistas nesse tipo de cultivo aceleraram a degradação dos solos e contribuíram para o êxodo rural na região.

Alguns autores, entre eles Derpsch et al. (1990), relatam que o sistema de preparo e cultivo convencional que impôs o uso de grade pesada até meados de 1985 e da prática de escarificação no período seguinte provocou a destruição das estruturas dos solos, o aumento do escoamento superficial, a diminuição da matéria orgânica, o empobrecimento de argila nos horizontes superficiais e, ainda, a subseqüente diminuição da fertilidade do solo, o que teria facilitado o desencadeamento dos processos erosivos laminares e lineares da região.
Para compreensão dos fatores responsáveis pela origem e evolução da erosão hídrica, é necessário que se conheça o comportamento da água na cobertura pedológica, já que este apresenta relações e mecanismos complexos, que envolvem tanto as propriedades físicas da água e dos fenômenos de interface água/partícula sólida e água/fase gasosa, responsáveis pela circulação e retenção de água, como as propriedades físicas e mecânicas dos solos que controlam os movimentos e a distribuição e, portanto, o seu comportamento no interior do solo e ao longo da vertente.

Outro aspecto a ser considerado é que essa água, além de não ser pura, está submetida a forças diversas, geralmente interdependentes. Essas forças, geradas pela gravidade, capilaridade e pelos fenômenos de interfaces, se manifestam, muito ou pouco, em função das variações rápidas das condições físicas do meio, o que torna as relações água/solo essencialmente dinâmicas. Cabe destacar, assim, o enfatizado por Riou (1990), quando este afirma que são os fatores físicos (altitude relativa, temperatura, concentração de sais, natureza das argilas e outros) que determinam o estado energético das soluções do solo em um dado lugar e num determinado tempo, condicionando os deslocamentos das moléculas de água.

$\mathrm{O}$ entendimento dessa complexidade de forças e mecanismos que envolvem o comportamento da água no solo só é possível se acompanhado do conhecimento integrado das características e do funcionamento nas coberturas pedológicas, o que pode ser obtido tanto em análises macro e micromorfológicas como por meio 
de medidas e ensaios do comportamento hídrico dos solos (Cunha et al., 1999). Essa necessidade tem sido indicada como imprescindível para a melhoria e adequação das propostas de controle preventivo e, ou, corretivo dos processos erosivos, já que suas ações devem permitir, de maneira adequada e segura, sua correta ocupação e manejo, por meio, sobretudo, do planejamento integrado de uso de seus recursos naturais.

Nesse contexto, com o conhecimento da organização dos materiais (nas escalas macro e micromorfológica), dos diferentes setores topográficos da toposseqüência "Campus do Arenito" no município de Cidade Gaúcha, noroeste do Estado do Paraná, realizados por meio do método da análise bidimensional da cobertura pedológica, preconizada por Boulet et al. (1982), definiu-se como objetivo deste estudo a caracterização do funcionamento hídrico dos materiais dessa vertente, partindo do pressuposto de que as dinâmicas destes podem contribuir para a evolução morfopedológica atual da vertente, bem como para compreender em que medida e por que condicionam e dão início à instalação dos processos erosivos laminares.

\section{MATERIAL E MÉTODOS}

A toposseqüência de solos "Campus do Arenito" localiza-se na fazenda Campus do Arenito, de propriedade da Universidade Estadual de Maringá, arredores do município de Cidade Gaúcha, região noroeste do Estado do Paraná, entre as coordenadas $52^{\circ} 23^{\prime}-53^{\circ} 00$ ' W e $23^{\circ} 19^{\prime}-23^{\circ} 25^{\prime} \mathrm{S}$.

O município de Cidade Gaúcha encontra-se em uma área de espigão, pertencente a um interflúvio de importância regional, delimitado pelos rios Ivaí e Piquiri. As altitudes variam de 200 a $400 \mathrm{~m}$, do fundo do vale até o topo do espigão, onde se encontra o sítio urbano de Cidade Gaúcha. Abrange uma área de $376 \mathrm{~km}^{2}$ e encontra-se circundado pelos córregos Ipiranga e Palmital, afluentes do rio Itaoca ou Pacu, que segue seu curso em direção ao rio Ivaí, ao norte do município.

Como a maioria das encostas do município, a vertente estudada apresenta-se longa, regular e convexa no segmento de topo. E caracterizada por declividades inferiores a $3 \%$ na alta vertente, passando para declividades entre 6 e $9 \%$ no setor de média-alta e entre 9 e $12 \%$ na baixa vertente.

A ocupação do solo, ao longo da vertente, é variada. $\mathrm{O}$ setor de alta vertente é utilizado por culturas temporárias, como o sorgo e o milho, seguido (no sentido de jusante) pelo cultivo de frutíferas variadas. O setor de média vertente é utilizado para o cultivo de milho e o de baixa vertente para o de cana-de-açúcar, particularmente nos últimos 15 anos (anteriormente era ocupado por pastagem).
A infiltração de água no solo foi determinada in situ nos seis perfis de solos da toposseqüência de solos Campus do Arenito em condições próximas de saturação. Foi utilizado o infiltrômetro multidisco com sucção controlada, denominado de TRIMS (Triple Rings Infiltrometers at Multiple Suctions), de acordo com as recomendações de White \& Sully (1987) e Grimaldi (1996).

Os ensaios foram realizados nas tensões $0,-1,-3 \mathrm{e}$ $-10 \mathrm{~cm} \mathrm{H}_{2} \mathrm{O}$ na superfície, na posição central dos horizontes diagnósticos, nas transições entre os horizontes A e $\mathrm{Bw}$ dos três perfis de Latossolo Vermelho eutrófico e nos horizontes AE e Bt dos três perfis do Argissolo Vermelho eutrófico, representados por Cunha (2002) na descrição morfológica (Quadro 1), nos atributos físicos (Quadro 2) e nos atributos químicos (Quadro 3). Cada horizonte, com exceção do horizonte A, foi exposto por escavação em pequenas trincheiras nos perfis de solos e preparado para instalação do equipamento.

Essa análise permite caracterizar o fluxo de água no interior do solo, distinguindo a infiltração dos grandes poros (biológicos ou interagregados) daquela que ocorre na matriz do solo (Perroux \& White, 1988). Mathieu \& Pieltain (1998), concordando com esse método, também o adaptaram ao estudo da variabilidade espacial das propriedades de infiltração.

As mensurações foram iniciadas pela superfície e depois nos respectivos degraus escavados na parede das pequenas trincheiras, sempre com o cuidado de preservar a superfície antes e durante a realização do ensaio. De acordo com Grimaldi (1996), o cuidado com a superfície de realização do ensaio é necessário, já que qualquer interferência (adensamento, retirada de matéria, acréscimo de matéria, retirada de raízes e outros) pode falsear o resultado.

Os ensaios foram realizados com cinco repetições, em pontos diferentes da mesma superfície (profundidade), sempre com o cuidado de retirar o aparelho a cada nova tensão, para que o recomeço da infiltração (ponto zero) fosse mantido naturalmente. Ao término de cada ponto, foram coletadas amostras em cilindros para avaliação da umidade do solo provocada pela água infiltrada durante o ensaio, bem como amostras para realização da curva característica de umidade, denominada de curva de retenção de água no solo.

Considerando a relação entre o potencial da água e o valor máximo $r$ do raio dos poros por ela ocupados, determinou-se, em face dos potenciais matriciais testados, o tamanho dos poros envolvidos em cada uma das tensões aplicando a seguinte equação:

$$
r=\frac{-2 \sigma \cos \alpha}{p g h} \approx \frac{-0,1482}{h}
$$

em que $\sigma=$ tensão superficial entre a água e o ar [MT-2]; $\alpha=$ ângulo de contato entre a água e a parede do poro; $p=$ densidade da água $\left[\mathrm{ML}^{-3}\right] ; g=$ aceleração devido à gravidade $\left[\mathrm{ML}^{-2}\right] ; h=$ pressão de água $\left(\mathrm{cm} \mathrm{H}_{2} \mathrm{O}\right) ;$ e $r=$ raio equivalente do poro $(\mathrm{em} \mathrm{cm})$. 
Quadro 1. Características morfológicas dos horizontes do sistema pedológico Campus do Arenito, Cidade Gaúcha-PR

\begin{tabular}{|c|c|c|c|c|c|c|}
\hline \multirow{2}{*}{ Horizonte } & \multicolumn{6}{|c|}{ Característica } \\
\hline & Cor & Textura & Estrutura & Porosidade & Consistência & Transição \\
\hline Ap & $\begin{array}{l}5 \mathrm{YR} 4 / 4 \\
5 \mathrm{YR} 3 / 3 \\
7,5 \mathrm{YR} 4 / 4\end{array}$ & Areia & $\begin{array}{l}\text { granular, } \\
\text { pequena e fraca }\end{array}$ & $\begin{array}{l}\text { Pequenos } \\
\text { com } \\
\text { pedotúbulos }\end{array}$ & $\begin{array}{l}\text { Seca = macia } \\
\text { úmida = solta } \\
\text { não-plástica e } \\
\text { não-pegajosa }\end{array}$ & $\begin{array}{l}\text { clara e } \\
\text { ondulada }\end{array}$ \\
\hline $\mathrm{AB} / \mathrm{BA}$ & $\begin{array}{l}5 \mathrm{YR} 3 / 3 \\
2,5 \mathrm{YR} 3 / 6\end{array}$ & $\begin{array}{l}\text { Areia } \\
\text { franca a } \\
\text { franco-arenosa }\end{array}$ & $\begin{array}{l}\text { blocos } \\
\text { poliédricos de } 2 \\
\text { a } 5 \mathrm{~cm} \text { de } \\
\text { diâmetro de } \\
\text { fraca a } \\
\text { moderada } \\
\text { resistência }\end{array}$ & $\begin{array}{l}\text { Muito } \\
\text { pequenos } \\
\text { com canais }\end{array}$ & $\begin{array}{l}\text { Seca = macia } \\
\text { úmida = solta } \\
\text { não-plástica e } \\
\text { não-pegajosa }\end{array}$ & Gradual plana \\
\hline $\mathrm{AE}$ & $\begin{array}{l}5 \text { YR } 4 / 4 \\
7,5 \text { YR } 4 / 4\end{array}$ & Areia & $\begin{array}{l}\text { granular, } \\
\text { pequena e fraca }\end{array}$ & $\begin{array}{l}\text { Pequenos } \\
\text { com canais e } \\
\text { pedotúbulos }\end{array}$ & $\begin{array}{l}\text { Seca = macia } \\
\text { úmida = solta } \\
\text { não-plástica e } \\
\text { não-pegajosa }\end{array}$ & $\begin{array}{l}\text { clara e } \\
\text { ondulada }\end{array}$ \\
\hline $\mathrm{Bw}_{1}$ & $2,5 \mathrm{YR} 3 / 4$ & $\begin{array}{l}\text { Areia } \\
\text { franca a } \\
\text { franco-argilo- } \\
\text { arenosa }\end{array}$ & $\begin{array}{l}\text { blocos angulares } \\
\text { de } 1 \text { a } 3 \mathrm{~cm} \text { de } \\
\text { diâmetro de } \\
\text { fraca resistência }\end{array}$ & $\begin{array}{l}\text { Pequenos } \\
\text { com canais e } \\
\text { pedotúbulos }\end{array}$ & $\begin{array}{l}\text { Seca = macia } \\
\text { úmida = solta } \\
\text { ligeiramente plástica } \\
\text { e ligeiramente } \\
\text { pegajosa }\end{array}$ & $\begin{array}{l}\text { clara e } \\
\text { ondulada }\end{array}$ \\
\hline $\mathrm{Bw}_{2}$ & $2,5 \mathrm{YR} 3 / 6$ & $\begin{array}{l}\text { Areia franca } \\
\text { a franco- } \\
\text { argilo- } \\
\text { arenosa }\end{array}$ & $\begin{array}{l}\text { blocos angulares } \\
\text { de } 3 \text { a } 5 \mathrm{~cm} \text { de } \\
\text { diâmetro de } \\
\text { moderada resistência }\end{array}$ & $\begin{array}{l}\text { Pequenos } \\
\text { com canais e } \\
\text { pedotúbulos }\end{array}$ & $\begin{array}{l}\text { Seca = macia } \\
\text { úmida }=\text { solta } \\
\text { ligeiramente plástica } \\
\text { e ligeiramente } \\
\text { pegajosa }\end{array}$ & $\begin{array}{l}\text { clara e } \\
\text { ondulada }\end{array}$ \\
\hline $\mathrm{Bw}_{3}$ & $2,5 \mathrm{YR} 3 / 6$ & $\begin{array}{l}\text { Franco- } \\
\text { arenosa }\end{array}$ & $\begin{array}{l}\text { blocos angulares } \\
\text { de } 3 \text { a } 5 \mathrm{~cm} \text { de } \\
\text { diâmetro de } \\
\text { moderada } \\
\text { resistência }\end{array}$ & $\begin{array}{l}\text { Pequenos } \\
\text { com canais e } \\
\text { pedotúbulos }\end{array}$ & $\begin{array}{l}\text { Seca = macia } \\
\text { úmida = solta } \\
\text { ligeiramente plástica } \\
\text { e ligeiramente } \\
\text { pegajosa }\end{array}$ & $\begin{array}{l}\text { clara e } \\
\text { ondulada }\end{array}$ \\
\hline $\mathrm{Bt}_{1}$ & $\begin{array}{l}2,5 \mathrm{YR} 3 / 6 \\
2,5 \mathrm{YR} 3 / 4\end{array}$ & $\begin{array}{l}\text { Franco- } \\
\text { arenosa a } \\
\text { franco-argilo- } \\
\text { arenosa }\end{array}$ & $\begin{array}{l}\text { blocos angulares } \\
\text { e subangulares } \\
\text { de até } 5 \mathrm{~cm} \text { de } \\
\text { diâmetro de } \\
\text { moderada resistência }\end{array}$ & $\begin{array}{l}\text { Muito } \\
\text { pequenos } \\
\text { com canais e } \\
\text { pedotúbulos }\end{array}$ & $\begin{array}{l}\text { Seca = ligeiramente } \\
\text { dura } \\
\text { úmida = firme } \\
\text { ligeiramente plástica } \\
\text { e pegajosa }\end{array}$ & $\begin{array}{l}\text { clara e } \\
\text { ondulada }\end{array}$ \\
\hline $\mathrm{Bt}_{2}$ & $\begin{array}{l}2,5 \mathrm{YR} 3 / 6 \\
2,5 \mathrm{YR} 3 / 4\end{array}$ & $\begin{array}{l}\text { Franco- } \\
\text { argilo-arenosa }\end{array}$ & $\begin{array}{l}\text { blocos angulares } \\
\text { e subangulares } \\
\text { de até } 5 \mathrm{~cm} \text { de } \\
\text { diâmetro de } \\
\text { forte resistência }\end{array}$ & $\begin{array}{l}\text { Muito } \\
\text { pequenos } \\
\text { com canais e } \\
\text { pedotúbulos }\end{array}$ & $\begin{array}{l}\text { Seca = ligeiramente } \\
\text { dura } \\
\text { úmida = firme } \\
\text { ligeiramente plástica } \\
\text { e pegajosa }\end{array}$ & $\begin{array}{l}\text { clara e } \\
\text { ondulada }\end{array}$ \\
\hline $\mathrm{Bt} 3$ & $\begin{array}{l}2,5 \mathrm{YR} 3 / 6 \\
2,5 \mathrm{YR} 3 / 4\end{array}$ & $\begin{array}{l}\text { Franco- } \\
\text { argilo-arenosa }\end{array}$ & $\begin{array}{l}\text { blocos angulares } \\
\text { e subangulares } \\
\text { de até } 5 \mathrm{~cm} \text { de } \\
\text { diâmetro de } \\
\text { moderada } \\
\text { resistência }\end{array}$ & $\begin{array}{l}\text { Muito } \\
\text { pequenos } \\
\text { com canais e } \\
\text { pedotúbulos }\end{array}$ & $\begin{array}{l}\text { Seca = ligeiramente } \\
\text { dura } \\
\text { úmida = firme } \\
\text { ligeiramente plástica } \\
\text { e pegajosa }\end{array}$ & $\begin{array}{l}\text { clara e } \\
\text { ondulada }\end{array}$ \\
\hline $\mathrm{C}$ & $2,5 \mathrm{YR} 3 / 6$ & Areia franca & $\begin{array}{l}\text { blocos angulares } \\
\text { e subangulares } \\
\text { de até } 3 \mathrm{~cm} \text { de } \\
\text { diâmetro de } \\
\text { fraca resistência }\end{array}$ & $\begin{array}{l}\text { Muito } \\
\text { pequenos }\end{array}$ & $\begin{array}{l}\text { Seca = macia } \\
\text { úmida = solta } \\
\text { ligeiramente plástica } \\
\text { e não-pegajosa }\end{array}$ & \\
\hline
\end{tabular}

Essa análise confirmou que no potencial $-1 \mathrm{~cm} \mathrm{H}_{2} \mathrm{O}$ só estão envolvidos os poros com raio equivalente ou inferior a $1,5 \mathrm{~mm}$; no potencial $-3 \mathrm{~cm} \mathrm{H} \mathrm{H}_{2} \mathrm{O}$, os poros com raio equivalente ou inferior a $0,5 \mathrm{~mm}$; e no potencial $-10 \mathrm{~cm} \mathrm{H}_{2} \mathrm{O}$, os poros com raio equivalente ou inferior a $0,15 \mathrm{~mm}$. Utilizando a classificação de
Brewer (1976), esses potenciais foram relacionados ao tamanho dos poros: macroporosidade média, fina e muito fina, respectivamente.

Para evidenciar o significado das variações obtidas nas medidas da condutividade hidráulica ao longo dos 
Quadro 2. Atributos físicos dos perfis de solos do sistema pedológico Campus do Arenito, Cidade Gaúcha-PR

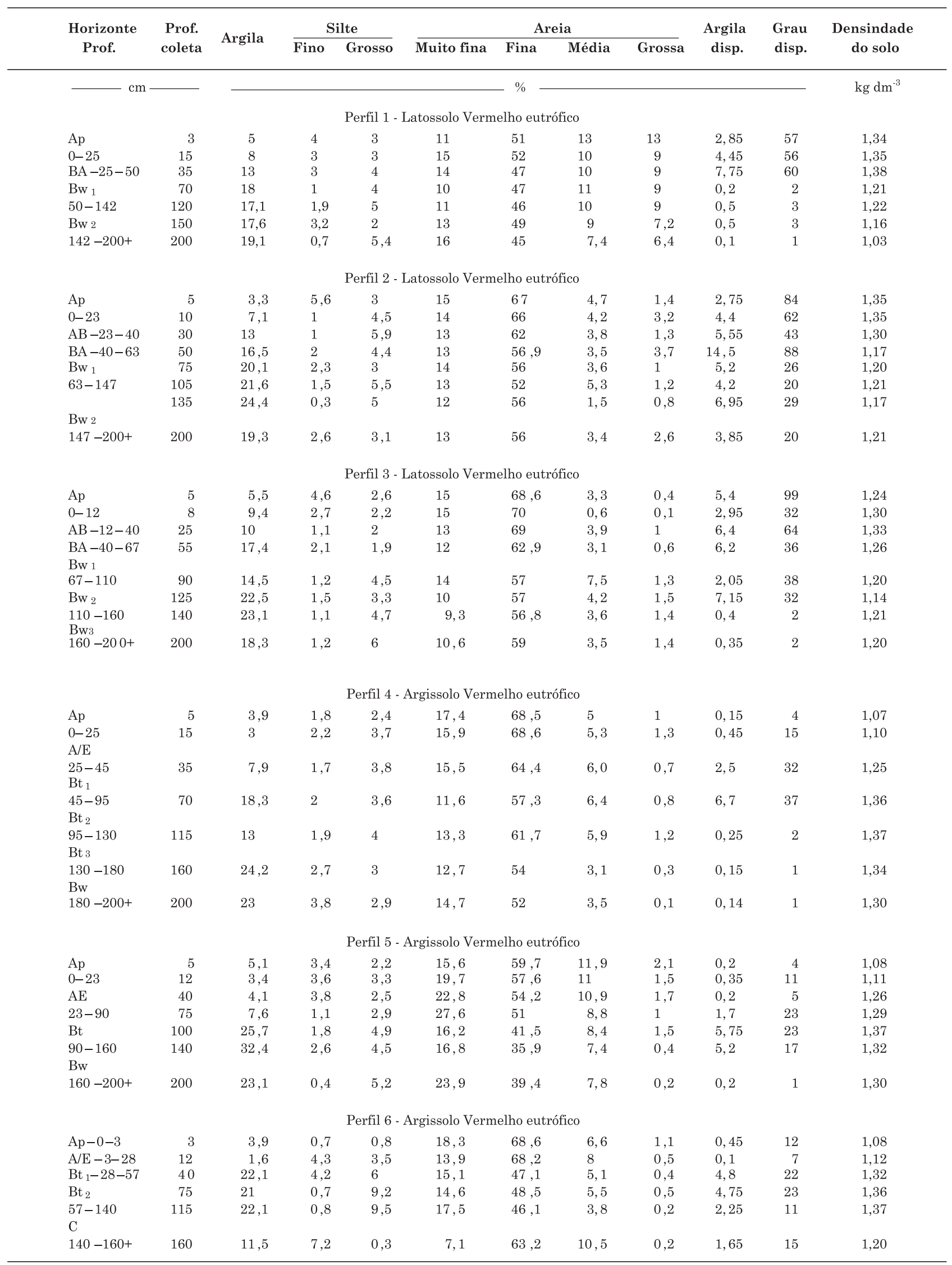


Quadro 3. Atributos químicos dos solos do sistema pedológico Campus do Arenito, Cidade Gaúcha-PR

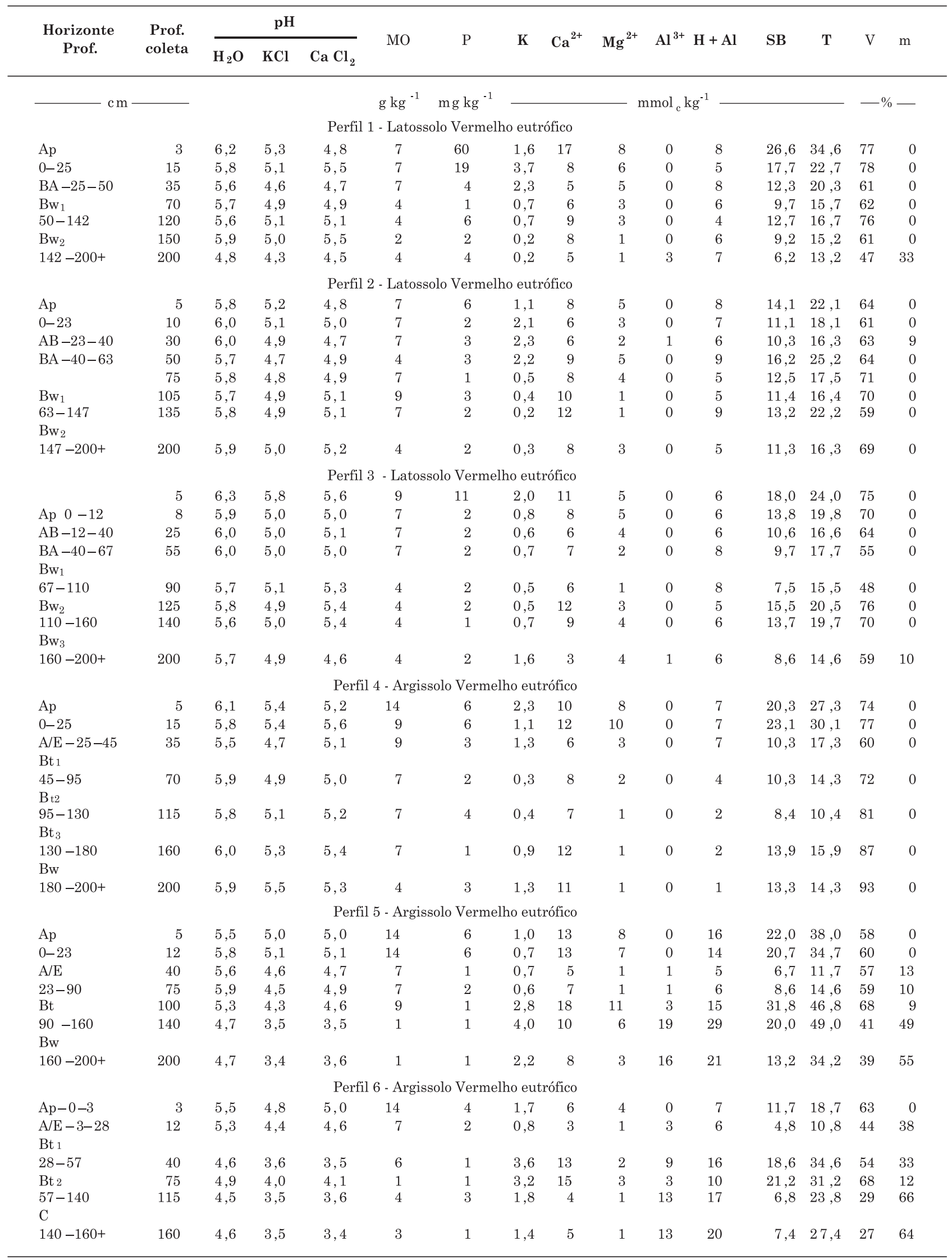


perfis e da toposseqüência, recorreu-se à classificação de percolação proposta por Aubert (1979) em função do coeficiente K (condutividade hidráulica) (Quadro 4).

Com o resultado dessa classificação, elaborou-se uma representação gráfica que permitiu a visualização das diferenças, para cada potencial matricial, por horizontes e perfis de solo.

Quadro 4. Classes de percolação em função do coeficiente K (conforme Aubert, 1979)

\begin{tabular}{|c|c|c|c|c|c|}
\hline \multirow{3}{*}{$\begin{array}{r}\begin{array}{r}\text { Velocidade } \\
\text { de filtração }\end{array} \\
\text { Muito lenta }\end{array}$} & \multicolumn{5}{|c|}{ Valores de $\mathrm{K}$} \\
\hline & \multicolumn{3}{|c|}{$10^{-5} \mathrm{~m} \mathrm{~s}^{-1}$} & \multicolumn{2}{|c|}{$\mathrm{cm} \mathrm{h}^{-1}$} \\
\hline & 0 & a & 0,03 & $0 \quad \mathrm{a}$ & 0,1 \\
\hline Lenta & 0,03 & a & 0,13 & $0,1 \mathrm{a}$ & 0,5 \\
\hline Bastante lenta & 0,13 & a & 0,55 & $0,5 \mathrm{a}$ & 2,0 \\
\hline Média & 0,55 & a & 1,8 & $2,0 \mathrm{a}$ & 6,5 \\
\hline Bastante rápida & 1,8 & a & 3,4 & 6,5 a & 12,5 \\
\hline Rápida & 3,4 & a & 6,9 & $12,5 \mathrm{a}$ & 25 \\
\hline Muito rápida & & $>$ & 6,9 & & 25 \\
\hline
\end{tabular}

\section{RESULTADOS E DISCUSSÃO}

A toposseqüência de solos Campus do Arenito estende-se numa vertente regular (sem rupturas nítidas de declive) convexa, com cerca de $860 \mathrm{~m}$ de comprimento. Apresenta declividades fracas, sendo $3 \%$ no setor de topo e terço superior, 6 a $9 \%$ no setor de média vertente e 9 a $12 \%$ no setor de baixa vertente (Figura 1). Do topo até a média vertente ocorre o Latossolo Vermelho eutrófico e, a partir deste setor até o sopé, o Argissolo Vermelho eutrófico, conforme nomenclatura da Embrapa (1999), constituindo um sistema pedológico Latossolo Vermelho eutrófico Argissolo Vermelho eutrófico.
Esse sistema é constituído por quatro horizontes diagnósticos ( $\mathrm{Ap}, \mathrm{Bw}, \mathrm{Bt}$ e $\mathrm{C})$, além do horizonte de transição ( $\mathrm{AB}$ e, ou, $\mathrm{BA}$ ) presente apenas na cobertura latossólica. Na cobertura argissólica ocorre um horizonte abaixo do A, que não pode ser representado lateralmente no desenho da toposseqüência devido à sua pequena espessura e fraca diferenciação vertical nos perfis observados (4, 5 e 6 ), mas que se evidenciou no campo na descrição morfológica (Quadro 1) e nas análises granulométricas (Quadro 2). Esse horizonte foi indicado como $\mathrm{AE}$ em virtude da semelhança que apresenta com o horizonte A.

Como a condutividade hidráulica expressa a capacidade que a água tem de se movimentar (infiltrar) no solo, para se compreender a dinâmica hídrica do sistema pedológico Campus do Arenito, foi necessário saber quais as condições de infiltração da água que o referido sistema apresenta (Figura 1).

A análise dos gráficos (Figura 2) revela que, na cobertura latossólica, do topo até a alta vertente (perfis 1 e 2), a parte superior dos solos (horizonte Ap) apresenta condutividade hidráulica mais baixa do que a parte inferior (horizonte Bw).

Na figura 3 , a representação mostra que, nessa parte superior dos perfis de solo 1 e 2, a infiltração tende a ser predominantemente muito lenta a bastante lenta. Ressalta, também, que há uma variação maior em termos de velocidade dos fluxos entre os horizontes superficiais e entre as tensões aplicadas. Nesse sentido, é possível dizer que nem sempre se reproduz a tendência verificada em profundidade, em que os fluxos mais rápidos estão associados aos potenciais - 1 (poros com $\mathrm{r} \leq 1,5 \mathrm{~mm}$ ), -3 (poros com $\mathrm{r} \leq 0,5 \mathrm{~mm}$ ) cm $\mathrm{H}_{2} \mathrm{O}$, e os mais lentos, ao potencial $-10 \mathrm{~cm} \mathrm{H}_{2} \mathrm{O}$ (poros com $\mathrm{r} \leq 0,15 \mathrm{~mm}$ ), respectivamente nas porosidades média, fina e muito fina.

Esses dados confirmam o que foi observado na micromorfologia e, também, o que já indicavam, em parte, os dados de caracterização física (Quadro 2).

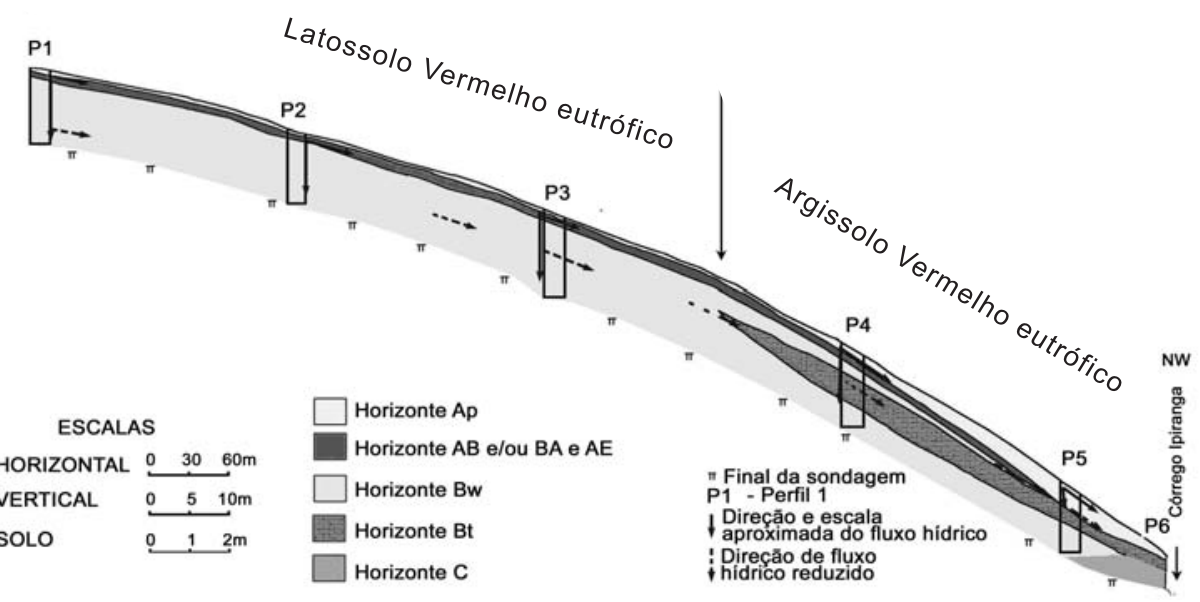

Figura 1. Toposseqüência de solos Campus do Arenito com a indicação dos fluxos hídricos. 

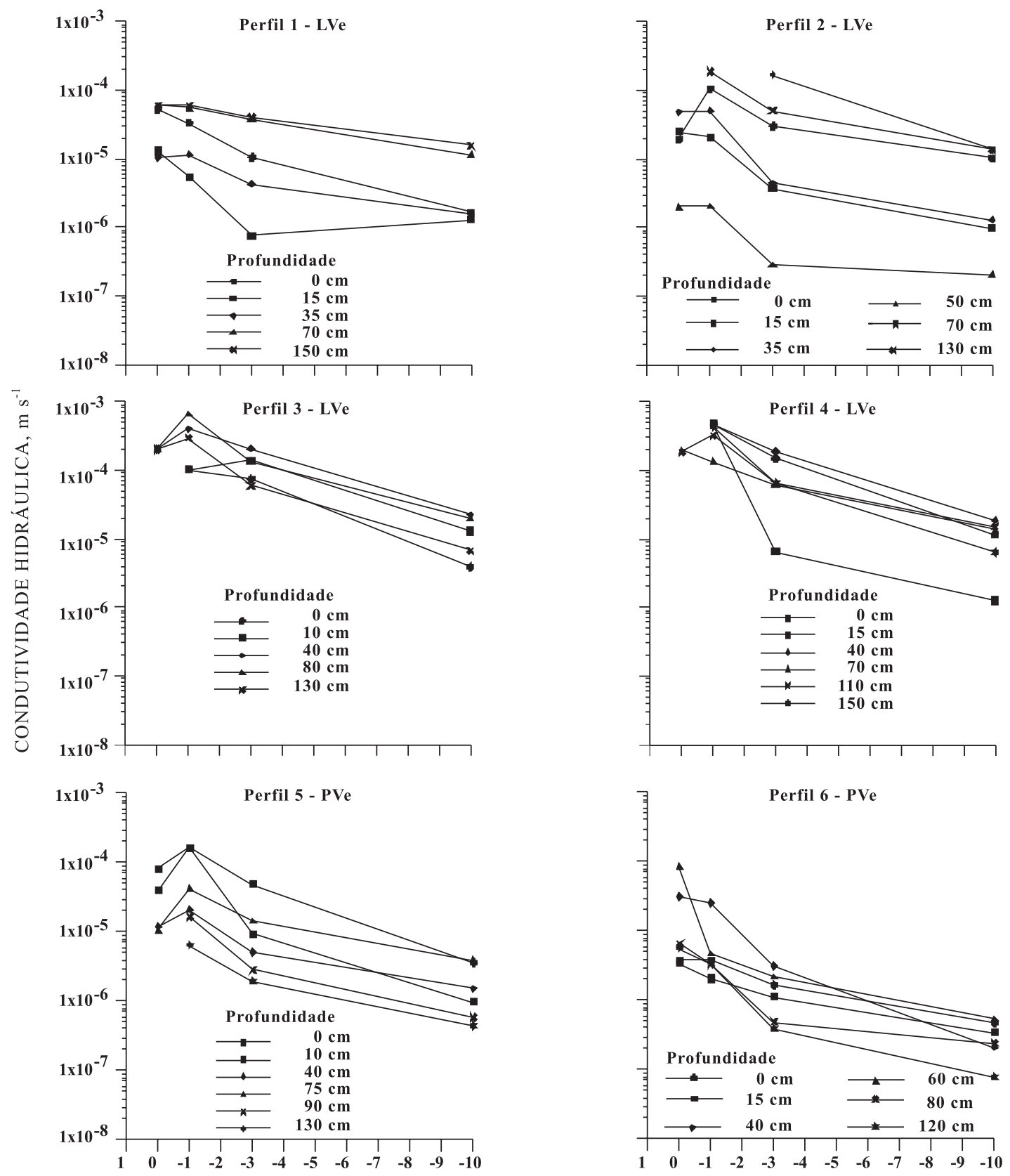

POTENCIAL MÁTRICO, $\mathrm{cm} \mathrm{H} \mathrm{H}_{2} \mathrm{O}$

Figura 2. Condutividade hidráulica dos perfis de solo da toposseqüência Campus do Arenito.

A micromorfologia evidenciou, nessa parte superior dos perfis, que, apesar de a estrutura de base ser predominantemente gefúrica e quito-gefúrica, há maior imbricamento dos grãos do esqueleto, o que aumenta a densidade do solo e reduz o raio dos poros e a conexão entre eles (Figura 4). Em conseqüência, há redução da porosidade total, o que leva à diminuição da condutividade hidráulica, com fluxos hídricos mais lentos, ao contrário das partes inferiores dos perfis, onde a drenagem é mais rápida.

No perfil 2, alta vertente, chama a atenção o que ocorre entre 40 e $63 \mathrm{~cm}$ de profundidade (horizonte
BA). Nesse horizonte, a condutividade hidráulica é drasticamente reduzida em relação ao resto do perfil, sob todos os potenciais matriciais medidos. Embora os dados de porosidade total e de índice de vazios sejam superiores àqueles dos horizontes sotopostos, as medidas de condutividade hidráulica indicam um freamento da circulação hídrica, explicado pelo imbricamento dos grãos do esqueleto observado na micromorfologia.

Nesse mesmo horizonte (BA) observou-se uma estrutura de base predominantemente porfirogrânica (porfirogrânica aberta em algumas zonas) e com 


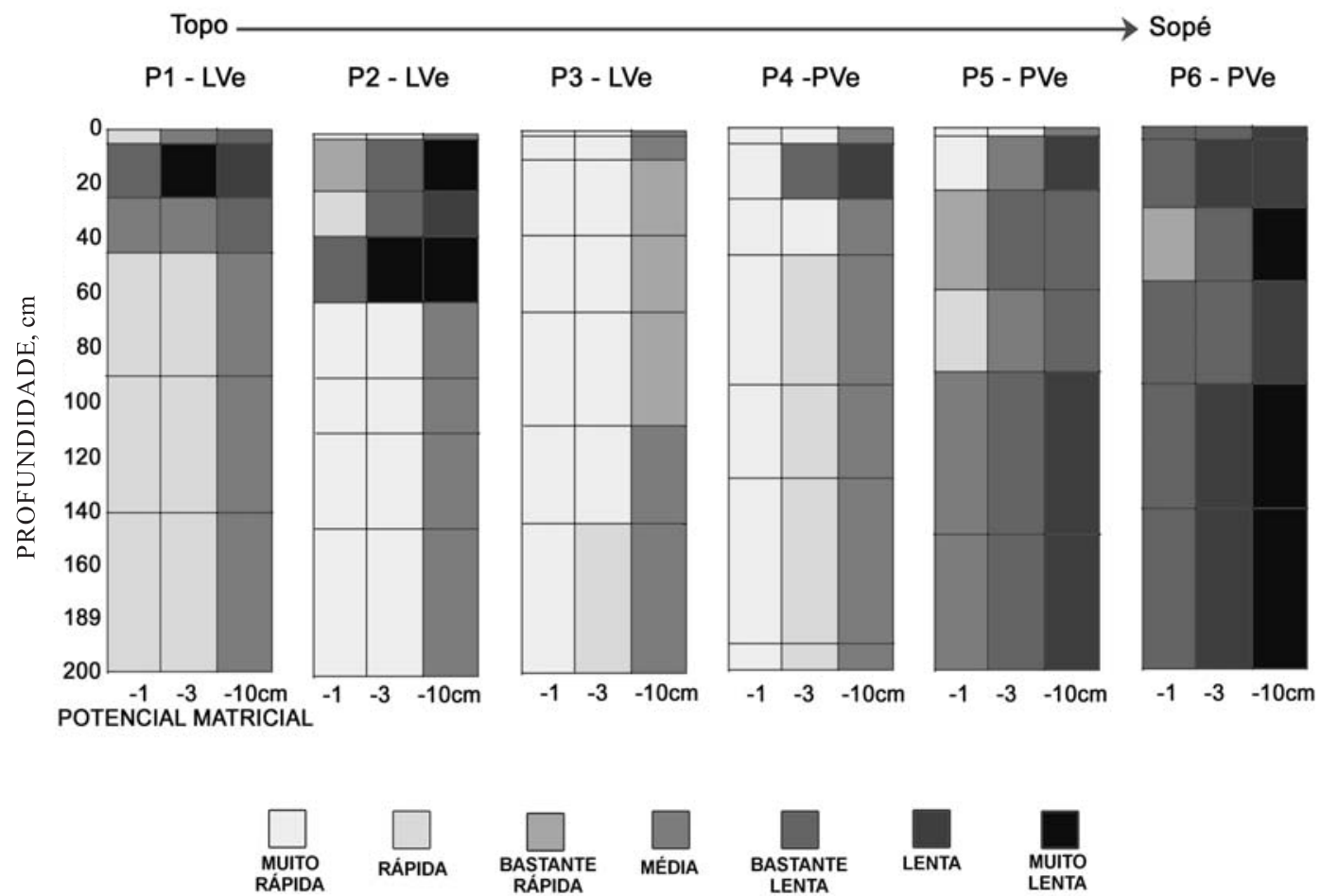

Figura 3. Classificação da condutividade hidráulica dos horizontes dos perfis de solo, conforme Aubert (1979).

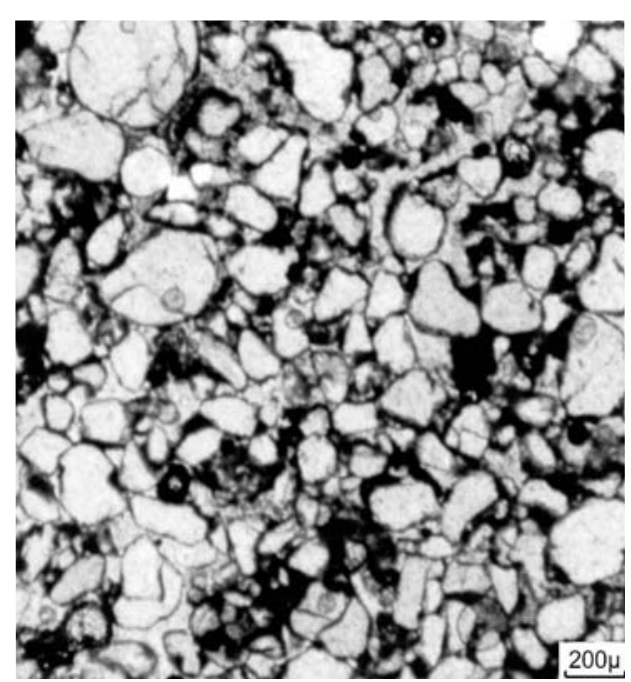

Figura 4. Imbricamento dos grãos do esqueleto nos horizontes superficiais (Ap e BA) do perfil 1.

alguns poucos setores enáulicos, porosidade cavitária e fracamente comunicante, macrocavidades irregulares não conectadas, fissuras finas e curtas cortando o plasma contínuo e no contato com os grãos do esqueleto, bem como fendas maiores cortando obliquamente o material (Figura 5). Esse horizonte apresenta, também, vários cutãs argiloférricos resultantes de iluviação e que atualmente colmatam a porosidade. Assim, apesar de a porosidade total ser mais alta do que aquela dos horizontes acima, ela está sendo bloqueada tanto pela iluviação quanto pela oclusão dos poros em conseqüência da transformação e do rearranjo dos agregados. A porosidade, dessa forma, perde conectividade. A instabilidade da estrutura é em parte corroborada pelo alto grau de dispersão da argila (88\%), o que facilitaria a destruição dos agregados e a formação de arranjos contínuos com setores porfirogrânicos fechados.

Em profundidade, já no horizonte Bw, a condutividade hidráulica aumenta, sendo predominantemente muito rápida e rápida para os potenciais mais

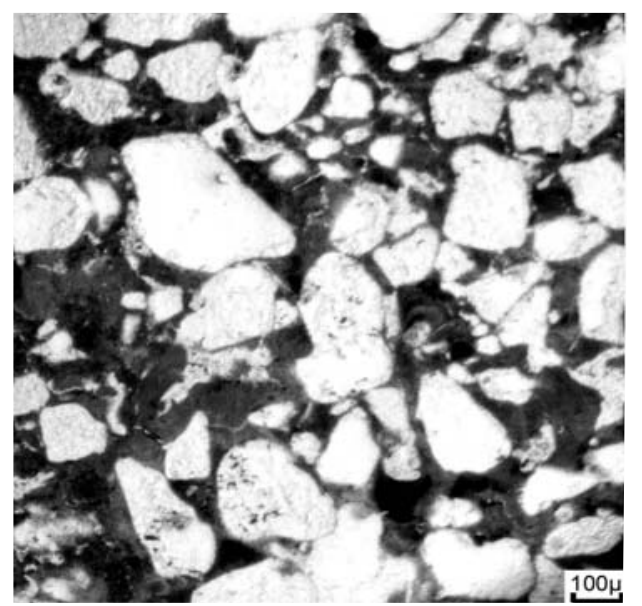

Figura 5. Estrutura de base porfirogrânica com porosidade cavitária e fissuras finas no horizonte BA do perfil 2. 
altos, e média para o potencial mais baixo. Considerando os dados apresentados, pode-se dizer que a condutividade hidráulica é, ainda, mais elevada na alta vertente (perfil 2) do que no topo (perfil 1). A infiltração se faz preferencialmente, como foi observado na micromorfologia, por meio de uma porosidade de empilhamento composto fortemente comunicante (Figura 6).

Os dados de densidade do solo (Quadro 2) também evidenciam essas condições de infiltração, pois, no Bw, nesse setor da vertente, independentemente do aumento do teor de argila vertical e lateral, os fluxos são mais rápidos, permitindo constatar que são as estruturas e o tipo de poros associados que estão condicionando aqui a circulação mais rápida da água.

Na média-alta vertente (perfil 3) a condutividade hidráulica apresenta-se globalmente mais elevada do que no setor a montante, e as diferenças entre os horizontes são menores. Entretanto, a parte superior do perfil (até $40 \mathrm{~cm}$ de profundidade) ainda apresenta uma condutividade hidráulica, em termos numéricos, ligeiramente mais reduzida em relação aos horizontes abaixo (Figura 2). A partir de $40 \mathrm{~cm}$ observa-se diminuição gradual da condutividade hidráulica em profundidade, que também se traduz em variação de classes de infiltração em face dos potenciais aplicados.

Observa-se, dessa forma, que, para a macroporosidade maior (potenciais 0 e $-1 \mathrm{~cm} \mathrm{H}_{2} \mathrm{O}$ ), os fluxos se mantêm muito rápidos ao longo de todo o perfil; para a macroporosidade fina os fluxos também são muito rápidos, passando a rápidos na base do perfil; para a macroporosidade muito fina, os fluxos têm velocidade média em superfície, passando a bastante rápidos nos horizontes de transição e, no topo do Bw abaixo, voltam a ter velocidade média.

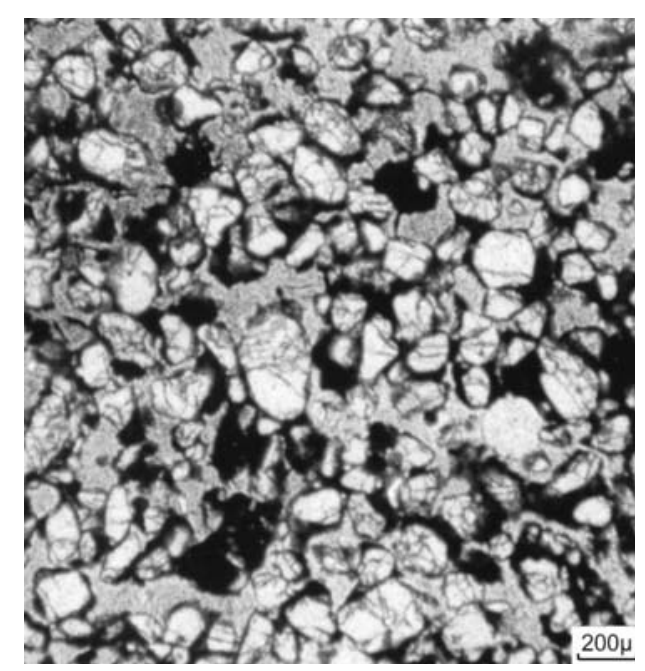

Figura 6. Porosidade de empilhamento composto fortemente comunicante no horizonte $\mathrm{Bw}$ do perfil 2.
As observações micromorfológicas nesse perfil evidenciaram a existência de uma macroporosidade importante, constituída por cavidades, fendas e canais. Em profundidade, apesar de uma estrutura pórfirogefúrica, com setores ora mais abertos ora mais fechados, a macroporosidade fissural e cavitária, menos interconectada, gera, ainda, ao lado da porosidade de empilhamento composto, uma condutividade hidráulica com fluxos rápidos a muito rápidos. Apenas sob potencial matricial mais baixo (envolvendo a macroporosidade muito fina) é que eles apresentam velocidade média.

Em direção à jusante, na média vertente, já no início da cobertura argissólica, a condutividade hidráulica apresenta características muito semelhantes às observadas no perfil 3 , a montante (Figura 2). Ressalta-se, assim, uma redução na velocidade dos fluxos no horizonte $\mathrm{A}$, envolvendo apenas os potenciais mais baixos $\left(-3 \mathrm{e}-10 \mathrm{~cm} \mathrm{H}_{2} \mathrm{O}\right)$. Em profundidade, a infiltração é muito rápida e rápida para os potenciais $0,-1$ e $-3 \mathrm{~cm} \mathrm{H}_{2} \mathrm{O}$, e média para o potencial mais baixo.

Também neste perfil (4), a micromorfologia evidenciou a existência de uma macroporosidade importante, formada por cavidades e fissuras, principalmente no horizonte $\mathrm{Bt}$, apesar da redução da porosidade total devido ao desenvolvimento maior das zonas porfirogrânicas e, ou, porfirogefúricas mais contínuas (Figura 7).

$\mathrm{Na}$ baixa vertente, as condições de circulação são novamente alteradas e os fluxos tornam-se, em direção à jusante e em profundidade, cada vez mais lentos. No perfil 5 (baixa vertente), os fluxos rápidos ou bastante rápidos só ocorrem na parte superior do perfil (horizontes A e AE), sob os potenciais matriciais maiores (0 e -1), associados, portanto, à macroporosidade grosseira e média. Nas macroporosidades fina e muito fina, a infiltração se faz com velocidades que se alternam nos horizontes entre média, bastante lenta, lenta e muito lenta. No horizonte Bt, mesmo sob potenciais mais elevados, a velocidade da infiltração é média para a macroporosidade maior e bastante lenta a lenta para a macroporosidade de menor tamanho.

A redução acentuada da condutividade hidráulica, a partir da baixa vertente até o sopé (Figura 2), ocorre associada ao aumento do teor de argila no Bt e com o desenvolvimento de uma estrutura essencialmente porfirogrânica fechada, com ocorrência de cutãs que colmatam a porosidade e ajudam a bloquear os fluxos.

De modo geral, a cobertura latossólica apresenta maior dificuldade de infiltração da água na parte superior (horizontes $\mathrm{A}$ e $\mathrm{AB}$ e, ou, $\mathrm{BA}$ ), no setor de alta (perfil 1) e média-alta vertente (perfil 2), criando, assim, condições para o desenvolvimento de fluxos hídricos laterais, acima deles (Figura 2). Essas constatações já foram feitas por Martins (2000) em seqüências de solos no município em estudo. Trabalhos realizados por Queiroz Neto et al. (1981), Manfredini \& Queiroz Neto (1993), Salomão (1994), Cooper (1999) 


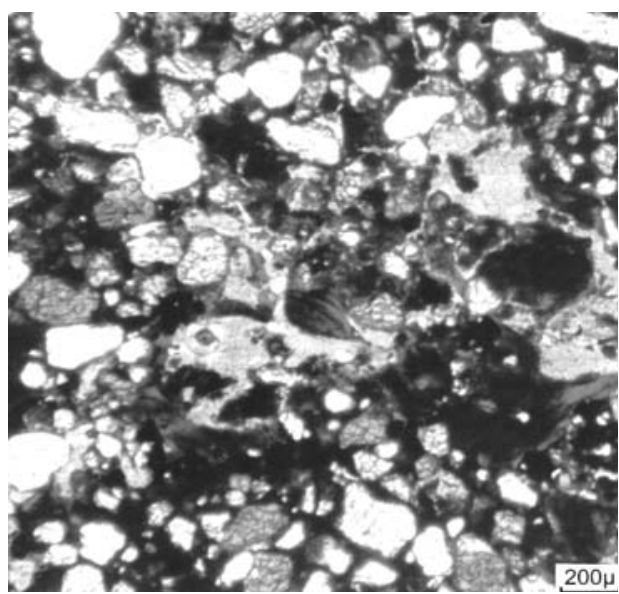

Figura 7. Macroporosidade formada por cavidades e fissuras e zonas porfirogrânicas e, ou, porfirogefúricas contínuas no horizonte Bt do perfil 4.

e Santos (2000), em coberturas pedológicas do Estado de São Paulo, também detectaram essas condições de circulação hídrica. Esse fato foi associado à compactação provocada pelo tipo de uso e manejo (culturas temporárias), com freqüente uso de máquinas, como já verificado por Silveira (2000) em Latossolos do município de Cidade Gaúcha. Em profundidade (horizonte Bw), os dados de condutividade mensurados confirmam as condições para o estabelecimento dos fluxos hídricos verticais. Situação semelhante foi descrita por Zago (2000) em Mamborê, também na região noroeste do Paraná.

$\mathrm{Na}$ transição da cobertura latossólica para a cobertura argissólica (perfil 3), o comportamento da condutividade hidráulica foi diferente daquele apresentado nos perfis 1 e 2 . No perfil 3, a infiltração foi maior ao longo de quase todo o perfil, indicando assim menor interferência do uso e do manejo do solo.

Grosso modo, na cobertura argissólica, apesar de a condutividade hidráulica ser globalmente menor do que na latossólica, ela apresenta um gradiente vertical (Figura 3), que cria condições para fluxos com maior velocidade na porção superior (horizonte AE e topo do Bt) e menores abaixo, gerando, portanto, fluxos hídricos laterais nos primeiros, que certamente atingem a capacidade de campo e mesmo saturam antes dos subjacentes. Condição semelhante a esta já foi verificada por Castro et al. (1993) e Zago (2000), dentre outros.

\section{CONCLUSÕES}

1. Na cobertura latossólica, nos horizontes A e AB e, ou, BA dos perfis 1 e 2, os fluxos hídricos são laterais, ao passo que no horizonte Bw eles são verticais.
2. Na cobertura argissólica, os fluxos hídricos ocorrem lateralmente e em maior velocidade na porção superior dos horizontes AE e Bt e vertical e em menor velocidade nas bases desses horizontes.

3. Na transição entre a cobertura latossólica e a cobertura argissólica ocorrem fluxos hídricos laterais suspensos, particularmente a partir da alta-média vertente (perfil 3) no horizonte $\mathrm{Bw}$, que se prolongam até a média vertente (perfil 4) no horizonte Bt.

\section{LITERATURA CITADA}

AUBERT, G. Méthodes d'analyses des sols. Marseille, CRDP, 1979. 171p.

BREWER, R. Fabric and mineral analysis of soils. 2.ed. New York, Krieger R. E., 1976. 482p.

BOULET, R.; CHAUVEL, A.; HUMBEL, F.X. \& LUCAS, Y. Analyse structurale et pédologie I. Prise em compte de l'organization bidimensionnelle de la couverture pédologique: lês études de toposéquences et leurs principaux apports à la connaissance dês sols. Cah. ORSTOM, Ser. Pédol. 19:309-322, 1982.

CASTRO, S.S.; HALLAIRE, V. \& CURMI, P. Macromorfologia de um Podzólico Vermelho-Amarelo de Marília (SP). In: CONGRESSO BRASILEIRO DE CIÊNCIA DO SOLO, 24., Goiânia. 1993. Anais. Goiânia, Sociedade Brasileira de Ciência do Solo, 1993. p.113-115.

COOPER, M. Influência das condições físico-hídricas nas transformações estruturais entre horizontes B latossólico e B textural sobre diabásio. Piracicaba, Escola Superior de Agricultura Luiz de Queiroz, 1999. 135p. (Tese de Doutorado)

CUNHA, J.E. Funcionamento hídrico e suscetibilidade erosiva de um sistema pedológico constituído por Latossolo e Argissolo no município de Cidade Gaúcha-PR. São Paulo, Universidade de São Paulo, 2002. 175p. (Tese de Doutorado)

CUNHA, J.E.; CASTRO, S.S. \& SALOMÃO, F.X.T. Comportamento erosivo de um sistema pedológico de Umuarama, noroeste do Estado do Paraná. R. Bras. Ci. Solo, 23:943-951, 1999.

DERPSCH, R.; ROTH, C.H.; SIDIRAS, N. \& KOPKE, U. Controle da erosão no Paraná, Brasil: Sistemas de cobertura do solo, plantio direto e preparo conservacionista do solo. Londrina, Instituto Agronômico do Paraná, 1990. 272p.

EMPRESA BRASILEIRA DE PESQUISA AGROPECUÁRIA EMBRAPA. Sistema brasileiro de classificação de solos. Brasília, Centro Nacional de Pesquisa de Solos/Serviço de Produção de Informação, 1999. 412p.

GRIMALDI, M. Proposition de travail sur le basin versant de Mamborê-PR. Misión de Michel Grimaldi dans la cadre du projet 151/94. CAPES/COFECUB, 1996. 
MANFREDINI, S. \& QUEIROZ NETO, J.P. Comportamento hídrico de sistema de transformação lateral B latossólico, B textural em Marília (SP). In: CONGRESSO BRASILEIRO DE CIÊNCIA DO SOLO, 24., Goiânia, 1993. Anais. Goiânia, Sociedade Brasileira de Ciência do Solo, 1993. p.91-93.

MARTINS, V.M. Caracterização morfológica e da circulação hídrica dos solos da cabeceira de drenagem do córrego Bom Jesus no município de Cidade Gaúcha- PR. DG/ FFLCH/USP. São Paulo, Universidade de São Paulo, 2000. 145p. (Tese de Mestrado)

MATHiEU, C. \& PIELTAIN, F. Analyse physique des sols. Méthodes choisies. Paris, Lavoisier Tec \& Doc., 1998. 275p.

PERROUX, K.M. \& WHITE, I. Design for disk permeameters. Soil Sci Soc. Am. J., 52:1205-1215, 1988.

QUEIROZ NETO, J.P.; CASTRO, S.S.; FERNANDES BARROS, O.N.; MANFREDINI, S.; PELLERIN, J.; RUELLAN, A. \& TOLEDO, G.S. Um estudo de dinâmica de solos: Formação e transformação de perfis com horizonte B textural. In: CONGRESSO BRASILEIRO DE CIÊNCIA DO SOLO, 17., Salvador, 1981. Anais. Salvador, Sociedade Brasileira de Ciência do Solo, 1981. CD-ROM.
RIOU, G. L'eau et lês sols. Dans lês géosystèmes tropicaux. Paris. Masson, 1990. 221p. (Colletion Géographie)

SALOMÃO, F.X.T. Processos erosivos lineares em Bauru (SP): regionalização cartográfica aplicada ao controle preventivo urbano e rural. São Paulo, Universidade de São Paulo, 1994. 200p. (Tese de Doutorado)

SANTOS, L.J.C. Pedogênese no topo do platô de Bauru (SP): O caso da bacia do córrego da Ponte Preta. São Paulo, Universidade de São Paulo, 2000. 183p. (Tese de Doutorado)

SILVEIRA, H. Modificações na estrutura e no comportamento hidrofísico de Latossolos provocados pelo uso e manejo no município de Cidade Gaúcha-Paraná. Rio Claro, Universidade Estadual de São Paulo, 2000. 97p. (Tese de Doutorado)

WHITE, I. \& SULLY, M.J. Macroscopic and microscopic capillary length and time scales from field infiltration. Water Res. Res., 23:1514-1522, 1987.

ZAGO, A. Sistema pedológico Latossolo-Argissolo e seu comportamento físico-hídrico em Mamborê, PR. São Paulo, Universidade de São Paulo, 2000. 161p. (Tese de Doutorado) 